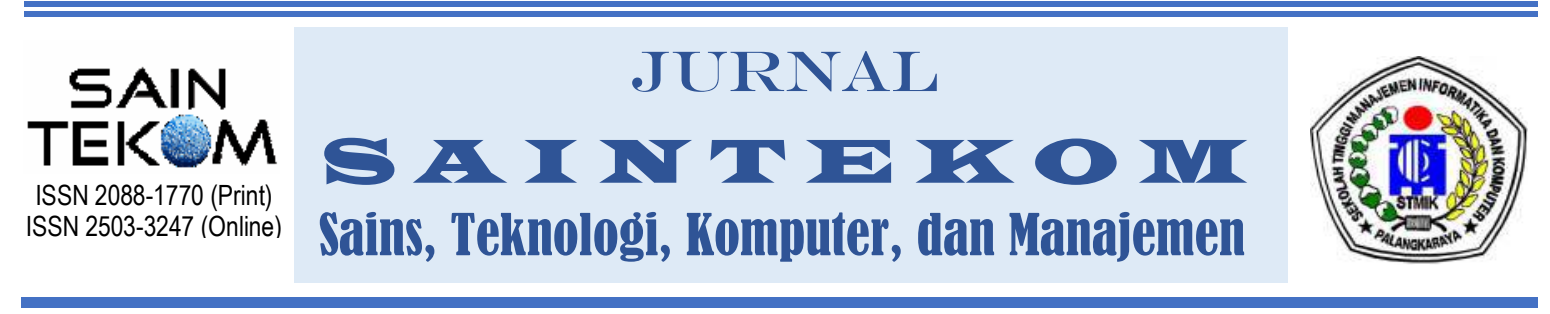

\title{
ANALISIS PENERIMAAN PENGGUNA E-RAPOR SMP MENGGUNAKAN EXTENDED TECHNOLOGY ACCEPTANCE MODEL
}

\author{
Gunawan ${ }^{1}$ dan Muhammad Rizki Zulkarnain ${ }^{2}$ \\ 1)Peternakan, Universitas Kristen Palangka Raya \\ Jl. RTA Milono Palangka Raya \\ 2)Pendidikan Teknologi Informasi, STKIP PGRI Banjarmasin \\ Jl. Sultan Adam Kompleks H. Iyus Banjarmasin \\ Email: gunawan.unkrip@gmail.com, rizkizulkarnain@stkipbjm.ac.id
}

\begin{abstract}
This study aims to analyze the user acceptance of junior high school e-Rapor using Extended Technology Acceptance Model (Extended TAM) by including Subjective Norms factor in the model. The research subjects were 60 e-Rapor users at public junior high school in Banjarmasin. Data collection instrument in the form of questionnaire consisting of 17 points of statement and using 5 point-Likert scale. The research data was analyzed using Partial Least Square-Structural Equation Modeling (PLS-SEM) with the assistance of SmartPLS 3.3.2 software. Based on the results of the study, it is known that Attitude towards Using Technology has a directly significant influence on the Behavioral Intention to use e-Rapor. On the contrary, Subjective Norms do not have a directly significant influence on the Behavioral Intention.
\end{abstract}

Keyword : Partial Least Square, Subjective Norms, Technology Acceptance Model

\begin{abstract}
ABSTRAK
Penelitian ini bertujuan untuk menganalisis penerimaan pengguna e-Rapor SMP menggunakan Ekstensi Model Penerimaan Teknologi dengan menyertakan faktor Norma Subyektif ke dalam model. Subyek penelitian ini adalah 60 orang pengguna e-Rapor SMP di SMP Negeri di Banjarmasin. Instrumen pengumpulan data berupa angket yang terdiri dari 17 butir pernyataan dan menggunakan skala Likert 5. Data penelitian dianalisis menggunakan Partial Least Square-Structural Equation Modeling (PLS-SEM) dengan bantuan aplikasi SmartPLS versi 3.3.2. Berdasarkan hasil penelitian, diketahui bahwa Sikap Menggunakan Teknologi berpengaruh signifikan terhadap Minat Menggunakan e-Rapor. Sebaliknya, Norma Subyektif tidak memiliki pengaruh yang signifikan terhadap Minat Menggunakan e-Rapor.
\end{abstract}

Kata kunci : Partial Least Square, Norma Subyektif, Model Penerimaan Teknologi 


\section{PENDAHULUAN}

Standar penilaian pendidikan pada pendidikan menengah mengacu pada Peraturan Menteri Pendidikan dan Kebudayaan Nomor 23 Tahun 2016 tentang Standar Penilaian Pendidikan. Penilaian pendidikan terdiri atas penilaian hasil belajar oleh pendidik, satuan pendidikan, dan pemerintah. Penilaian hasil belajar oleh pendidik bertujuan untuk memantau dan mengevaluasi proses, kemajuan belajar, dan perbaikan hasil belajar peserta didik secara berkesinambungan. Penilaian hasil belajar peserta didik meliputi aspek sikap, pengetahuan, dan keterampilan. Prosedur penilaian hasil belajar oleh pendidik berawal dari menetapkan tujuan penilaian, hingga melaporkan hasil penilaian dan memanfaatkan laporan hasil penilaian.

Pelaporan hasil belajar peserta didik akan lebih komprehensif, lebih akurat, dan cepat dilakukan apabila didukung oleh perangkat komputer. Berkaitan dengan hal tersebut, sejak tahun 2017 Kementerian Pendidikan dan Kebudayaan melalui Direktorat Pembinaan Sekolah Menengah Pertama mengembangkan e-Rapor SMP beserta panduan penggunaannya. e-Rapor SMP kini telah terintegrasi dengan Data
Pokok Pendidikan

(Dapodik)

(Kementerian Pendidikan dan Kebudayaan, 2017). Kehadiran e-Rapor SMP diharapkan dapat membantu para pendidik dalam melakukan penilaian hasil belajar peserta didik. Pada penerapannya, pendidik, dalam hal ini, guru diharapkan untuk dapat menguasai penggunaan e-Rapor SMP sesegera mungkin. Namun bagi sebagian guru diperlukan proses yang lebih lama dibanding yang lain untuk dapat menguasai cara menggunakannya. Banyak sistem teknologi informasi yang gagal karena aspek teknisnya. Namun, meskipun kualitas sistem sudah membaik, tetapi masih banyak terdengar sistem teknologi informasi yang gagal diterapkan. Penelitianpenelitian menunjukkan bahwa penyebab kegagalan suatu sistem teknologi informasi adalah lebih pada aspek keprilakuannya (behavior). Masih banyak terdengar bahwa sistem teknologi informasi gagal diterapkan karena manusianya menolak atau tidak mau menggunakannya dengan banyak alasan. Menolak menggunakan sistem adalah suatu perilaku (Hartono, 2007). Oleh karena itu, peneliti tertarik untuk melakukan analisis penerimaan e-Rapor SMP dan mengetahui faktor-faktor yang 
mempengaruhi minat menggunakan eRapor di masa yang akan datang.

\section{METODE}

Penelitian ini bertujuan untuk melakukan analisis penerimaan pengguna Aplikasi e-Rapor SMP di SMP Negeri di Banjarmasin. Analisis penerimaan e-Rapor pada penelitian ini menggunakan pendekatan Extended Technology Acceptance Model (Extended TAM) dengan menyertakan konstruk Norma Subyektif (Subjective Norms) pada model.

Konstruk, disebut juga sebagai variabel laten, adalah suatu ukuran yang abstrak, tidak dapat diamati secara langsung. Konstruk dijelaskan oleh indikator-indikator atau disebut juga variabel manifest, yang dapat teramati secara langsung (Juliandi, 2018; Sarstedt et al., 2017). Konstrukkonstruk yang digunakan pada penelitian ini adalah konstruk Norma Subyektif (Subjective Norms), konstruk Kemudahan Penggunaan Persepsian (Perceived Ease of Use), konstruk Kegunaan Persepsian (Perceived Usefulnes), konstruk Sikap Menggunakan Teknologi (Attitude towards Using Technology), dan konstruk Minat Perilaku Menggunakan
Teknologi (Behavioral Intention to Use).

Pada penelitian ini, peneliti menggunakan Partial Least Square Structural Equation Modeling (PLSSEM). Hair et al. (2014) mengemukakan bahwa tahapan yang dilakukan pada PLS-SEM adalah:

a. Spesifikasi Model;

b. Evaluasi Outer Model (Evaluasi Measurement Model atau Model Pengukuran);

c. Evaluasi Inner Model (Evaluasi Structural Model atau Model Struktural).

Adapun model yang digunakan pada penelitian ini, dapat dilihat pada Gambar 1 berikut, merupakan model reflektif.

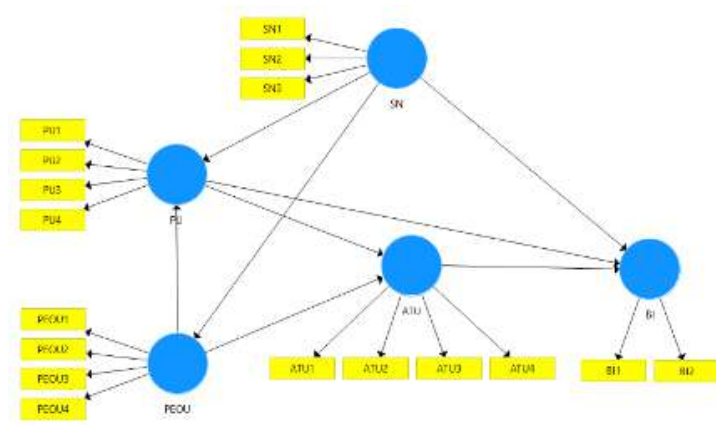

Gambar 1. Model yang Diteliti

Fornell dan Bookstein (1982) dalam Ghozali (2014) menyatakan bahwa konstruk seperti "personalitas" atai "sikap" umumnya dipandang sebagai faktor yang menimbulkan 
sesuatu yang kita amati sehingga indikatornya bersifat refleksif. Ghozali (2014) menjelaskan bahwa pada model reflektif, indikator merupakan manisfestasi dari konstruk, arah hubungan kausalitas dari konstruk ke indikator, dan menghilangkan satu indikator tidak akan mengubah makna atau arti konstruk.

Pada tahapan Evaluasi Outer Model (Measurement Model atau Model Pengukuran), kriteria-kriteria yang perlu diperhatikan adalah:

a. Indicator reliability;

b. Internal consistency reliability;

c. Convergent validity;

d. Discriminant validity (Sarstedt et al., 2017).

Selanjutnya, pada tahapan Evaluasi Inner Model (Structural Model atau Model Struktural), dapat dilihat mengenai:

a. $R^{2}$ explanation of endogenous latent variables;

b. Significance and relevance of path coefficients (Sarstedt et al., 2017).

Jenis penelitian yang dilakukan adalah penelitian kuantitatif. Subjek dalam penelitian ini adalah 60 orang pengguna e-Rapor SMP di SMP Negeri di Banjarmasin yang bersedia menjadi responden, terdiri dari 22 responden laki-laki dan 38 responden perempuan.

Dari 60 responden tersebut, 3 orang bertugas sebagai admin, 29 orang bertugas sebagai guru mata pelajaran sekaligus wali kelas, 26 orang sebagai guru mata pelajaran saja, dan 1 orang bertugas guru mata pelajaran, wali kelas, sekaligus admin. Sebanyak 2 responden tidak memberikan keterangan mengenai usianya, 12 responden berada pada rentang usia 20 hingga 29 tahun, 10 responden pada rentang usia 30 hingga 39 tahun, 15 responden pada rentang usia 40 hingga 49 tahun, dan sisanya sebanyak 21 orang berusia 50 tahun atau lebih.

Instrumen pengumpulan data berupa lembar angket terdiri dari 17 butir pernyataan dan menggunakan skala Likert 5. Berikut daftar butir pernyataan yang dicantumkan pada lembar angket.

Tabel 1. Nilai Loading dan Indicator

\begin{tabular}{|c|l|l|}
\hline \multicolumn{2}{|c}{ Reliability } \\
\hline Konstruk & \multicolumn{1}{|c|}{$\begin{array}{c}\text { Indikator/ } \\
\text { Pernyataan }\end{array}$} & Simbol \\
\hline $\begin{array}{c}\text { Kemudahan } \\
\text { Penggunaan } \\
\text { Persepsian } \\
\text { (Perceived }\end{array}$ & $\begin{array}{l}\text { Mudah bagi } \\
\text { saya untuk } \\
\text { mempelajari }\end{array}$ & \\
Ease of Use/ & cara & PEOU1 \\
PEOU) & menggunakan e- & \\
& Rapor. & \\
\cline { 2 - 3 } & Mudah bagi & \\
& saya untuk & \\
& melakukan apa & PEOU2 \\
& yang saya ingin & \\
& lakukan pada e- & \\
& Rapor. & \\
\hline
\end{tabular}

Jurnal Saintekom, Vol.11, No.2, September 2021 


\begin{tabular}{|c|c|c|}
\hline Konstruk & $\begin{array}{l}\text { Indikator/ } \\
\text { Pernyataan }\end{array}$ & Simbol \\
\hline & $\begin{array}{l}\text { Mudah bagi } \\
\text { saya untuk } \\
\text { menjadi } \\
\text { terampil dalam } \\
\text { menggunakan e- } \\
\text { Rapor. }\end{array}$ & PEOU3 \\
\hline & $\begin{array}{l}\text { e-Rapor mudah } \\
\text { untuk } \\
\text { digunakan. }\end{array}$ & PEOU4 \\
\hline \multirow[t]{4}{*}{$\begin{array}{l}\text { Kegunaan } \\
\text { Persepsian } \\
\text { (Perceived } \\
\text { Usefulnes/ } \\
\text { PU) }\end{array}$} & $\begin{array}{l}\text { Menggunakan } \\
\text { e-Rapor } \\
\text { memungkinkan } \\
\text { saya } \\
\text { menyelesaikan } \\
\text { pekerjaan } \\
\text { dengan lebih } \\
\text { cepat. }\end{array}$ & PU1 \\
\hline & $\begin{array}{l}\text { Menggunakan } \\
\text { e-Rapor } \\
\text { meningkatkan } \\
\text { kinerja saya. }\end{array}$ & PU2 \\
\hline & $\begin{array}{l}\text { Menggunakan } \\
\text { e-Rapor } \\
\text { mempermudah } \\
\text { pekerjaan saya. }\end{array}$ & PU3 \\
\hline & $\begin{array}{l}\text { e-Rapor } \\
\text { bermanfaat bagi } \\
\text { saya. }\end{array}$ & PU4 \\
\hline \multirow{4}{*}{$\begin{array}{c}\text { Sikap } \\
\text { Menggunakan } \\
\text { Teknologi } \\
\text { (Attitude } \\
\text { towards } \\
\text { Using } \\
\text { Technology/ } \\
\text { ATU) }\end{array}$} & $\begin{array}{l}\text { Menggunakan } \\
\text { e-Rapor } \\
\text { merupakan ide } \\
\text { yang bagus. }\end{array}$ & ATU1 \\
\hline & $\begin{array}{l}\text { Menggunakan } \\
\text { e-Rapor } \\
\text { merupakan } \\
\text { tindakan yang } \\
\text { bijaksana. }\end{array}$ & ATU2 \\
\hline & $\begin{array}{l}\text { e-Rapor } \\
\text { membuat } \\
\text { pekerjaan } \\
\text { menjadi lebih } \\
\text { menarik. }\end{array}$ & ATU3 \\
\hline & $\begin{array}{l}\text { Bekerja dengan } \\
\text { e-Rapor itu } \\
\text { menyenangkan. }\end{array}$ & ATU4 \\
\hline \multirow[t]{2}{*}{$\begin{array}{c}\text { Minat } \\
\text { Perilaku } \\
\text { Menggunakan } \\
\text { Teknologi } \\
\text { (Behavioral } \\
\text { Intention to } \\
\text { Use/ BI) }\end{array}$} & $\begin{array}{l}\text { Saya } \\
\text { memperkirakan } \\
\text { saya akan tetap } \\
\text { menggunakan e- } \\
\text { Rapor dalam } 12 \\
\text { bulan ke depan. }\end{array}$ & BI1 \\
\hline & $\begin{array}{l}\text { Saya berharap } \\
\text { untuk terus } \\
\text { menggunakan e- }\end{array}$ & $\mathrm{BI} 2$ \\
\hline
\end{tabular}

\begin{tabular}{|c|c|c|}
\hline Konstruk & $\begin{array}{c}\text { Indikator/ } \\
\text { Pernyataan }\end{array}$ & Simbol \\
\hline & Rapor. & \\
\hline \multirow[t]{3}{*}{$\begin{array}{c}\text { Norma } \\
\text { Subyektif } \\
\text { (Subjective } \\
\text { Norms) }\end{array}$} & $\begin{array}{l}\text { Keluarga atau } \\
\text { sahabat saya } \\
\text { berpendapat } \\
\text { bahwa saya } \\
\text { sebaiknya } \\
\text { menggunakan e- } \\
\text { Rapor. }\end{array}$ & SN1 \\
\hline & $\begin{array}{l}\text { Rekan kerja } \\
\text { saya } \\
\text { menyarankan } \\
\text { kepada saya } \\
\text { untuk } \\
\text { menggunakan e- } \\
\text { Rapor. }\end{array}$ & SN2 \\
\hline & $\begin{array}{l}\text { Pimpinan } \\
\text { sekolah } \\
\text { mendukung } \\
\text { penggunaan e- } \\
\text { Rapor. }\end{array}$ & SN3 \\
\hline
\end{tabular}

(Sumber: Davis, 1989; Davis, et al., 1989; Park, 2009; Venkatesh \& Bala, 2008)

Data pada penelitian ini dianalisis dengan menggunakan software SmartPLS 3.3.2

\section{HASIL DAN PEMBAHASAN}

\section{Evaluasi Outer Model (Measurement}

\section{Model atau Model Pengukuran)}

$$
\text { Algoritma PLS (estimasi) }
$$

pertama belum menunjukkan hasil yang baik, sehingga ada indikator yang perlu dihilangkan dari model, yaitu indikator ATU3, ATU4, PEOU4, PU3, PU4, dan SN1. Selanjutnya dilakukan perhitungan (estimasi) yang kedua.

Hasil pengolahan data yang menunjukkan indicator reliability dapat dilihat pada Tabel 2. 
Tabel 2. Nilai Loading dan Indicator Reliability

\begin{tabular}{|c|c|c|}
\hline Indikator & $\begin{array}{c}\text { Indicator } \\
\text { (Outer) } \\
\text { Loading }\end{array}$ & $\begin{array}{c}\text { Indicator } \\
\text { Reliability }\end{array}$ \\
\hline ATU1 & 0,902 & 0,814 \\
\hline ATU2 & 0,886 & 0,785 \\
\hline BI1 & 0,937 & 0,878 \\
\hline BI2 & 0,958 & 0,918 \\
\hline PEOU1 & 0,883 & 0,780 \\
\hline PEOU2 & 0,765 & 0,585 \\
\hline PEOU3 & 0,876 & 0,767 \\
\hline PU1 & 0,918 & 0,843 \\
\hline PU2 & 0,921 & 0,848 \\
\hline SN2 & 0,932 & 0,869 \\
\hline SN3 & 0,933 & 0,870 \\
\hline
\end{tabular}

Suatu indikator dengan nilai loading di atas 0,7 (atau setara dengan nilai indicator reliability di atas 0,5 ) memiliki reliabilitas yang baik (Sarstedt et al., 2017; Kalinzi, 2019). Pada Tabel 2 di atas dapat dilihat bahwa setiap indikator yang ada telah memiliki reliabilitas yang baik.

Selanjutnya, internal consistency reliability suatu konstruk ditunjukkan oleh nilai Cronbach's $\alpha, \rho_{A}$, dan Composite Reliability $\left(\rho_{C}\right)$ masingmasing konstruk, disajikan pada Tabel 3.

Tabel 3. Nilai Cronbach's $\alpha, \rho_{A}$, dan Composite Reliability $\left(\rho_{C}\right)$

\begin{tabular}{|c|c|c|c|}
\hline Konstruk & $\begin{array}{c}\text { Cronbach's } \\
\alpha\end{array}$ & $\rho_{A}$ & $\begin{array}{c}\text { Composite } \\
\text { Reliability } \\
\left(\rho_{C}\right)\end{array}$ \\
\hline ATU & 0,749 & 0,751 & 0,888 \\
\hline BI & 0,888 & 0,914 & 0,946 \\
\hline PEOU & 0,797 & 0,820 & 0,880 \\
\hline PU & 0,817 & 0,817 & 0,916 \\
\hline SN & 0,850 & 0,851 & 0,930 \\
\hline
\end{tabular}

Suatu konstruk dengan nilai Cronbach's $\alpha$ sebesar $\quad 0,70$ sampai dengan 0,90 , nilai $\rho_{A}$ lebih dari 0,70 , dan nilai $\rho_{C}$ sebesar 0,70 sampai dengan 0,95 menunjukkan internal consistency reliability yang baik (Sarstedt et al., 2017). Pada Tabel 3 di atas dapat dilihat bahwa setiap konstruk telah memiliki internal consistency reliability yang baik.

Selanjutnya, convergent validity suatu konstruk dapat dilihat melalui nilai Average Variance Extracted (AVE) masing-masing konstruk, ditunjukkan pada Tabel 4.

Tabel 4. Nilai AVE

\begin{tabular}{|c|c|}
\hline Konstruk & AVE \\
\hline ATU & 0,799 \\
\hline BI & 0,898 \\
\hline PEOU & 0,711 \\
\hline PU & 0,845 \\
\hline SN & 0,870 \\
\hline
\end{tabular}

Suatu konstruk dengan nilai AVE 0,50 atau lebih menunjukkan convergent validity yang baik (Sarstedt et al., 2017). Pada Tabel 4 di atas dapat dilihat bahwa setiap konstruk telah memiliki convergent validity yang baik.

Selanjutnya, discriminat validity dapat dilihat dari nilai Cross Loadings, Fornell-Larcker Criterion, dan Heterotrait-Monotrait Ratio (HTMT), 
masing-masing disajikan pada Tabel 5, Tabel 6, dan Tabel 7 berikut.

Tabel 5. Cross Loadings

\begin{tabular}{|c|c|c|c|c|c|}
\hline & ATU & BI & PEOU & PU & SN \\
\hline ATU1 & 0,902 & 0,574 & 0,454 & 0,617 & 0,536 \\
\hline ATU2 & 0,886 & 0,489 & 0,592 & 0,547 & 0,555 \\
\hline BI1 & 0,485 & 0,937 & 0,276 & 0,152 & 0,292 \\
\hline BI2 & 0,632 & 0,958 & 0,426 & 0,346 & 0,444 \\
\hline PEOU1 & 0,529 & 0,397 & 0,883 & 0,651 & 0,546 \\
\hline PEOU2 & 0,488 & 0,323 & 0,765 & 0,411 & 0,344 \\
\hline PEOU3 & 0,461 & 0,234 & 0,876 & 0,671 & 0,402 \\
\hline PU1 & 0,610 & 0,202 & 0,636 & 0,918 & 0,469 \\
\hline PU2 & 0,590 & 0,299 & 0,647 & 0,921 & 0,442 \\
\hline SN2 & 0,577 & 0,390 & 0,499 & 0,428 & 0,932 \\
\hline SN3 & 0,561 & 0,349 & 0,471 & 0,495 & 0,933 \\
\hline \multicolumn{7}{|l}{}
\end{tabular}

Pada Tabel 5 dapat dilihat bahwa setiap blok indikator memiliki nilai loading lebih tinggi untuk setiap konstruk yang diukur, dibandingkan dengan indikator untuk konstruk lainnya.

Tabel 6. Fornell-Larcker Criterion

\begin{tabular}{|c|c|c|c|c|c|}
\hline & ATU & BI & PEOU & PU & SN \\
\hline ATU & 0,894 & & & & \\
\hline BI & 0,596 & 0,948 & & & \\
\hline PEOU & 0,582 & 0,378 & 0,843 & & \\
\hline PU & 0,652 & 0,273 & 0,698 & 0,919 & \\
\hline SN & 0,610 & 0,396 & 0,520 & 0,495 & 0,933 \\
\hline
\end{tabular}

Keterangan: nilai pada diagonal utama (memiliki warna berbeda) merupakan akar kuadrat dari AVE

Jika nilai akar kuadrat AVE setiap konstruk lebih besar dapada nilai korelasi antara konstruk dengan konstruk lainnya, maka konstuk memiliki discriminant validity yang baik (Hair et al., 2014). Pada Tabel 6 di atas dapat dilihat bahwa setiap konstruk telah memiliki discriminant validity yang baik.

Tabel 7. Heterotrait-Monotrait Ratio (HTMT)

\begin{tabular}{|c|c|c|c|c|c|}
\hline & ATU & BI & PEOU & PU & SN \\
\hline ATU & & & & & \\
\hline BI & 0,720 & & & & \\
\hline PEOU & 0,760 & 0,440 & & & \\
\hline PU & 0,833 & 0,308 & 0,849 & & \\
\hline SN & 0,765 & 0,447 & 0,620 & 0,594 & \\
\hline
\end{tabular}

Nilai HTMT di bawah 0,85 menunjukkan discriminant validity yang baik (Henseler et al. 2015; Sarstedt et al., 2017). Pada Tabel 7 di atas dapat dilihat bahwa setiap konstruk telah memiliki discriminant validity yang baik.

\section{Evaluasi Inner Model (Structural}

\section{Model atau Model Struktural)}

Nilai $\mathrm{R}^{2}$ untuk konstruk endogen dapat dilihat pada Tabel 8 .

Tabel 8. Nilai $\mathrm{R}^{2}$

\begin{tabular}{|c|c|}
\hline Konstruk & $\mathrm{R}^{2}$ \\
\hline ATU & 0,457 \\
\hline BI & 0,383 \\
\hline PEOU & 0,270 \\
\hline PU & 0,511 \\
\hline
\end{tabular}

Berdasarkan Tabel 8 di atas dapat diketahui bahwa:

a. Konstruk PU dan PEOU mampu menjelaskan konstruk ATU sebesar $45,7 \%$, sedangkan sisanya sebesar $54,3 \%$ dijelaskan oleh faktor lain 
yang tidak diteliti pada penelitian ini.

b. Konstruk SN, PU, dan ATU menjelaskan konstruk BI sebesar $38,3 \%$, sedangkan sisanya sebesar $61,7 \%$ dijelaskan oleh faktor lain yang tidak diteliti pada penelitian ini.

c. Konstruk SN mampu menjelaskan konstruk PEOU sebesar 27,0\%, sedangkan sisanya sebesar $73,0 \%$ dijelaskan oleh faktor lain yang tidak diteliti pada penelitian ini.

d. Konstruk SN dan PEOU mampu menjelaskan konstruk PU sebesar $51,1 \%$, sedangkan sisanya sebesar $48,9 \%$ dijelaskan oleh faktor lain yang tidak diteliti pada penelitian ini.

Selanjutnya dilakukan prosedur bootstraping (resampling menjadi 500 subsampel) dan melakukan pengujian dua arah dengan tingkat signifikansi $5 \%$. Hasil pengujian yang diperoleh dapat dilihat pada Tabel 9 berikut.

Tabel 9. Signifikansi Koefisien Jalur

\begin{tabular}{|c|c|c|c|}
\hline & $\begin{array}{c}\text { Sampel } \\
\text { Asli (O) }\end{array}$ & $\begin{array}{c}\text { T Stat } \\
(\mid \mathrm{O} / \\
\text { STDEV } \\
\mid)\end{array}$ & Nilai P \\
\hline $\mathrm{SN} \rightarrow \mathrm{PU}$ & 0,181 & 1,634 & 0,103 \\
\hline $\begin{array}{c}\mathrm{SN} \rightarrow \\
\mathrm{PEOU}\end{array}$ & 0,520 & 5,646 & 0,000 \\
\hline $\mathrm{SN} \rightarrow \mathrm{BI}$ & 0,085 & 0,531 & 0,595 \\
\hline $\mathrm{PU} \rightarrow \mathrm{BI}$ & $-0,216$ & 1,331 & 0,184 \\
\hline
\end{tabular}

\begin{tabular}{|c|c|c|c|}
\hline & $\begin{array}{c}\text { Sampel } \\
\text { Asli (O) }\end{array}$ & $\begin{array}{c}\text { T Stat } \\
(\mid \mathrm{O} / \\
\text { STDEV } \\
\mid)\end{array}$ & Nilai P \\
\hline $\mathrm{PU} \rightarrow$ ATU & 0,479 & 3,927 & 0,000 \\
\hline $\begin{array}{c}\text { PEOU } \rightarrow \\
\text { PU }\end{array}$ & 0,604 & 6,329 & 0,000 \\
\hline $\begin{array}{c}\text { PEOU } \rightarrow \\
\text { ATU }\end{array}$ & 0,248 & 1,789 & 0,074 \\
\hline ATU $\rightarrow$ BI & 0,685 & 4,373 & 0,000 \\
\hline
\end{tabular}

Dari Tabel 9 di atas dapat dilihat bahwa:

a. Konstruk SN tidak berpengaruh signifikan terhadap konstruk PU, dilihat dari nilai $\mathrm{P}$ lebih dari 0,05 yaitu sebesar 0,103.

b. Konstruk SN berpengaruh signifikan terhadap dilihat PEOU, dilihat dari nilai $\mathrm{P}$ kurang dari 0,05 yaitu sebesar 0,000 .

c. Konstruk SN tidak berpengaruh signifikan terhadap konstruk BI, dilihat dari nilai $\mathrm{P}$ lebih dari 0,05 yaitu sebesar 0,595.

d. Konstruk PU tidak berpengaruh signifikan terhadap konstruk BI, dilihat dari nilai $\mathrm{P}$ lebih dari 0,05 yaitu sebesar 0,184.

e. Konstruk PU berpengaruh signifikan terhadap konstruk ATU, dilihat dari nilai $\mathrm{P}$ kurang dari 0,05 yaitu sebesar 0,000 .

f. Konstruk PEOU berpengaruh signifikan terhadap konstruk PU 
dilihat dari nilai $\mathrm{P}$ kurang dari 0,05 yaitu sebesar 0,000 .

g. Konstruk PEOU tidak berpengaruh signifikan terhadap konstruk ATU, dilihat dari nilai $\mathrm{P}$ lebih dari 0,05 yaitu sebesar 0,074.

h. Konstruk ATU berpengaruh signifikan terhadap konstruk BI, dilihat dari nilai $\mathrm{P}$ kurang dari 0,05 yaitu sebesar 0,000 .

\section{SIMPULAN}

Dari hasil penelitian yang telah diperoleh, dapat diketahui bahwa:

a. Sikap Menggunakan Teknologi (Attitude Toward Using Technology) berpengaruh signifikan terhadap Minat Menggunakan Teknologi (Behavioral Intention to Use). Hal ini berarti evaluasi kepercayaan (belief) atau perasaan (affect) positif atau negatif dari seseorang jika harus menggunakan e-Rapor mempengaruhi minat dirinya untuk menggunakan e-Rapor. Meningkatkan atau menurunkan evaluasi kepercayaan (belief) atau perasaan (affect) positif atau negatif dari seseorang jika harus menggunakan e-Rapor akan meningkatkan atau menurunkan minatnya untuk menggunakan eRapor.

b. Norma Subjektif (Subjective Norms) tidak berpengaruh signifikan terhadap Minat Menggunakan Teknologi (Behavioral Intention to Use). Hal ini berarti persepsi atau pandangan seseorang terhadap tekanan sosial (kepercayaankepercayaan orang lain) tidak mempengaruhi minat dirinya untuk menggunakan e-Rapor. Meningkatkan atau menurunkan persepsi seseorang terhadap tekanan sosial (kepercayaan orang lain) mengenai penggunaan e-Rapor tidak akan meningkatkan atau menurunkan minatnya untuk menggunakan e-Rapor.

\section{UCAPAN TERIMA KASIH}

Tim peneliti mengucapkan terima kasih yang sebesar-besarnya atas dukungan semua pihak yang terlibat, di antaranya:

a. Direktorat Riset dan Pengabdian Masyarakat (DRPM), Deputi Bidang Penguatan Riset dan Pengembangan, Kementerian Riset dan Teknologi/ Badan Riset dan Inovasi Nasional.

b. Dinas Pendidikan Kota Banjarmasin. 
c. SMPN Se-Kota Banjarmasin, khususnya SMPN 5, SMPN 23, dan SMPN 34 Banjarmasin.

\section{DAFTAR PUSTAKA}

Davis, F. D. 1989. Perceived Usefulness, Perceived Ease of Use, and User Acceptance of Information Technology. MIS Quarterly, 13 (3), 319-340.

Davis, F. D., Bagozzi, R. P., \& Warshaw, P. R. 1989. User Acceptance of Computer Technology: A Comparison of Two Theoretical Models. Management Science, 35 (8), 982-1003.

Ghozali, I. 2014. Structural Equation Modeling, Metode Alternatif dengan Partial Least Square (PLS), Edisi 4. Semarang: Universitas Diponegoro.

Hair, J. F., Sarstedt, M., Hopkins, L., \& Kuppelwieser, V. G. 2014. Partial Least Squares Structural Equation Modeling (PLS-SEM), An emerging tool in business research, European Business Review, 26 (2), 106-121.

Hartono, J. 2007. Sistem Informasi Keperilakuan. $\quad$ Yogyakarta: ANDI.

Henseler, J., Ringle, C. M., \& Sarstedt, M. 2015. A New Criterion for Assessing Discriminant Validity in Variance-Based Structural Equation. Journal of The Academy of Marketing Science, 43 (1), 115-135.
Juliandi, A. 2018. Structural Equation Model Partial Least Square (SEM-PLS): Menggunakan SmartPLS. Pelatihan SEM-PLS Program Pascasarjana Universitas Batam on December,16-17 2018. Batam: Universitas Batam. DOI: 10.5281/zenodo. 2538001

Kalinzi, C. 2019. Re: What does indicator's reliability indicate in PLS SEM specially in smart PLS results?. Retrieved from: https://www.researchgate.net/po st/What-does-indicatorsreliability-indicate-in-PLS-SEMspecially-in-smart-PLSresults $/ 5$ dc18383aalf0950d904d 4a2/citation/download.

Kementerian Pendidikan dan Kebudayaan. 2017. Panduan eRapor SMP. Jakarta: Direktorat Jenderal Pendidikan Dasar dan Menengah.

Park, S. Y. 2009. An Analysis of the Technology Acceptance Model in Understanding University Students' Behavioral Intention to Use e-Learning. Educational Technology \& Society, 12 (3), 150-162.

Peraturan Menteri Pendidikan dan Kebudayaan Nomor 23 Tahun 2016 tentang Standar Penilaian Pendidikan.

Ringle, C. M., Wende, S., dan Becker, J.M. 2015. SmartPLS 3. Boenningstedt: SmartPLS $\mathrm{GmbH}$, http://www.smartpls.com. 
Sarstedt, M., Hair, J., \& Ringle, C. M. 2017. Partial Least Squares Structural Equation Modeling, https://www.researchgate.net/pu blication/319669432_Partial_Le ast_Squares_Structural_Equatio n_Modeling, diakses pada tanggal 8 Desember 2020.

Venkatesh, V. \& Bala, H. 2008. Technology Acceptance Model 3 and a Research Agenda on Interventions. Decision Sciences, 39 (2), 273-315. 